\title{
Hubungan Durasi Paparan Media Elektronik Terhadap Pola Tidur Anak Usia 10-13 Tahun
}

Maudina Hati Fatimah Diantoro, Dimas Tri Anantyo, Farid Agung Rahmadi

Departemen Ilmu Kesehatan Anak Fakultas Kedokteran Universitas Diponegoro, Semarang

Latar belakang. Diperkirakan setiap tahunnya terjadi peningkatan prevalensi gangguan tidur sesuai dengan peningkatan usia dan berbagai faktor penyebabnya. Paparan media elektronik berlebihan dapat berpengaruh pada masalah kesehatan. Penelitian di 5 negara termasuk Indonesia tahun 2012 menunjukkan bahwa lebih dari 80\% anak usia 10-13 tahun telah memiliki akses telepon selular pribadi. American Academy of Pediatrics menyarankan durasi paparan media elektronik pada balita dan anak prasekolah selama 1 jam atau kurang dan remaja selama 2 jam atau kurang per hari.

Tujuan. menganalisis hubungan antara durasi paparan media elektronik dengan munculnya gangguan tidur pada anak usia 10-13 tahun Metode. penelitian belah lintang dengan subjek penelitian dari beberapa SD di Semarang pada April - Juli 2019. Subjek penelitian melengkapi kuesioner 3DPAR) untuk menilai durasi paparan media elektronik serta orangtua mengisi kuesioner SDSC untuk menilai gangguan tidur. Analisis bivariat menggunakan uji Chi-square dengan nilai signifikansi $\mathrm{p}<0,05$.

Hasil. Dari 90 responden didapatkan 76 responden $(84,4 \%)$ dengan paparan media elektronik lebih dari 2 jam perhari dan terdapat 65 responden $(72,2 \%)$ mengalami gangguan tidur. Terdapat hubungan bermakna antara durasi paparan media elektronik dengan gangguan tidur. Kesimpulan. Durasi paparan media elektronik lebih dari 2 jam perhari memiliki hubungan yang bermakna dengan gangguan tidur anak usia 10-13 tahun. Sari Pediatri 2021;22(6):359-63

Kata kunci: gangguan tidur, durasi paparan media elektronik

\section{The Association between Electronic Media Exposure Duration to Sleep Patterns of Children Aged 10-13 Years Old}

Maudina Hati Fatimah Diantoro, Dimas Tri Anantyo, Farid Agung Rahmadi

Background. Sleep disorders can affect a person's daily conditions. It is estimated that every year there is an increase in the prevalence of sleep disorders in accordance with the increase in age and various causes. Excessive electronic media exposure can affect health problems and behaviors. Research conducted in 5 countries including Indonesia in 2012 showed that more than $80 \%$ of children aged 10-13 years old already have their own accessible mobile phone. According to the American Academy of Pediatrics, the recommended duration of electronic media exposure in toddlers and preschoolers is 1 hour or less a day and in adolescents is 2 hours or less a day.

Objective. Analyzing the association between the electronic media exposure duration to sleep patterns of children aged 10-13 years old.

Methods. Cross-sectional study with the subjects from several elementary schools in Tembalang, Semarang in April - July 2019. Subjects accompanied by parents completed the 3DPAR questionnaire (Three Day Physical Activity Recall to assess the duration of exposure to electronic media and parents fill out the SDSC (Sleep Disturbance Scale for Children) questionnaire to assess sleep disorders. Bivariate analysis using test Chi-square with a significance value of $\mathrm{p}<0.05$.

Results. Number of samples in this study was 90 respondents. There were 76 respondents $(84.4 \%)$ with electronic media exposure more than 2 hours per day and there were 65 respondents (72.2\%) who experienced sleep disorders. There was a significant association between the duration of electronic media exposure with sleep disturbance. There was no significant association between sleep disturbance with lighting during sleep, noise during sleep and placement of television in the bedroom.

Conclusion. Duration of exposure to electronic media for more than 2 hours per day has a significant relationship with sleep disorders of children aged 10-13 years old. Sari Pediatri 2021;22(6):359-63

Keywords sleep disorders, duration of exposure to electronic media

Alamat korespondensi: Farid Agung Rahmadi, Departemen Ilmu Kesehatan Anak Fakultas Kedokteran UNDIP Jln. Prof H. Soedarto, SH, Tembalang,Semarang. Email : faridrhmd@gmail.com 
$\mathrm{T}$ idur merupakan hal dasar yang sangat dibutuhkan. Adanya gangguan tidur dapat menimbulkan berbagai macam gangguan, seperti proses belajar, memori, serta prestasi sekolah yang memengaruhi kondisi keseharian seorang individu, baik pada anak, remaja, maupun dewasa. ${ }^{1}$ Penelitian yang dilakukan di Indonesia pada tahun 2009 dengan responden remaja usia 12-15 tahun didapatkan bahwa gangguan tidur terjadi pada $62,9 \%$ responden. ${ }^{2}$ Penelitian yang dilakukan pada tahun 2011 dengan responden remaja usia 12-15 tahun didapatkan gangguan tidur $62,5 \% .^{3}$

Menurut data terbaru, 30 juta anak dan remaja di Indonesia merupakan pengguna internet dan media elektronik. Saat ini, media elektronik menjadi pilihan utama saluran komunikasi yang digunakan. Sebesar $79,5 \%$ anak dan remaja di Indonesia merupakan pengguna internet dan $67 \%$ di antaranya telah memiliki telepon genggam pribadi. ${ }^{4}$ Penelitian yang dilakukan di lima negara termasuk Indonesia pada tahun 2012 menunjukkan bahwa lebih dari $80 \%$ anak usia 10-13 tahun telah memiliki akses telepon selular pribadi. ${ }^{5}$

Media elektronik merupakan alat teknologi komunikasi, baik berupa televisi, laptop, komputer, dan gawai. Paparan berlebih penggunaan media elektronik dapat berpengaruh pada masalah kesehatan dan tingkah laku. Menurut American Academy of Pediatrics (AAP), saran durasi paparan media elektronik pada balita dan anak prasekolah adalah selama satu jam atau kurang dari satu jam per hari dan pada remaja adalah selama dua jam atau kurang dari dua jam per hari. ${ }^{6}$

Berdasarkan latar belakang yang dipaparkan, penelitian ini bertujuan untuk mengetahui hubungan durasi paparan media elektronik lebih dari dua jam terhadap pola tidur anak usai 10-13 tahun dan hubungan durasi paparan media elektronik kurang dari dua jam terhadap pola tidur anak usia 10-13 tahun.

\section{Metode}

Penelitian desain potong lintang dengan anak berusia 10-13 tahun secara purposive sampling. Besar sampel minimal yang diperlukan adalah 90 anak berusia $10-13$ tahun dari 4 sekolah dasar di Tembalang, Semarang dan bersedia mengikuti penelitian dengan mengisi informed consent yang dilanjutkan dengan pengisian kuesioner 3DPAR (3 Day Physical Activity Recall) oleh anak untuk mendapat data durasi paparan media elektronik perhari serta kuesioner SDSC (Sleep Disturbance Scale for Children) yang diisi oleh orang tua atau pengasuh untuk menilai ada atau tidaknya gangguan pola tidur.

Data pencahayaan yang digunakan saat tidur, suara bising yang mengganggu tidur, serta penempatan televisi di dalam kamar juga dianalisis dalam penelitian ini.

Kelayakan etik diperoleh dari Komisi Etik Penelitian Kesehatan (KEPK) Fakultas Kedokteran Universitas Diponegoro no. 138 sebagai tanda persetujuan penelitian serta informed concent yang didapatkan dari orang tua. Data yang didapat dilakukan pengolahan menggunakan program komputer dengan hipotesis hubungan durasi paparan media elektronik terhadap pola tidur akan diuji menggunakan uji Chi-square dengan nilai signifikansi $\mathrm{p}<0,005$.

\section{Hasil}

Penelitian telah dilakukan dari bulan April hingga Juli 2019 dengan sampel penelitian 90 anak berusia 10-13 tahun dengan karakteristik responden tertera pada Tabel 1.

Pada Tabel 1, jumlah responden laki-laki 30 $(33,3 \%)$ dan perempuan 60 (66,7\%) dengan kelompok usia termuda 10 tahun dan tertua 15 tahun. Responden dengan kelompok usia 10 tahun berjumlah $46(51,1 \%)$, usia 11 tahun $25(27,8 \%)$, usia 12 tahun $3(3,3 \%)$, dan usia 13 tahun $16(17,8 \%)$ orang. Sejumlah 14 $(15,6 \%)$ subjek menggunakan media elektronik dengan durasi kurang dari 2 jam perhari, sedangkan 76 $(84,4 \%)$ dengan durasi lebih dari 2 jam perhari. Media elektronik meliputi televisi, laptop, komputer, dan gawai (handphone, tablet PC, hingga video games). Sejumlah $50(55,6 \%)$ orang menyalakan lampu saat tidur dan $40(44,6 \%)$ mematikan lampu saat tidur. Terdapat $31(34,4 \%)$ menyatakan terdapat suara bising yang mengganggu saat tidur dan $59(65,5 \%)$ menyatakan tidak terdapat suara bising yang mengganggu saat tidur.

Suara bising meliputi seluruh suara yang dianggap mengganggu saat tidur seperti suara bising kendaraan di jalan raya, suara rel kereta api ataupun suara tangisan bayi. Sejumlah $47(52,2 \%)$ responden memiliki televisi yang ditempatkan di dalam kamar dan dinyalakan saat tidur sedangkan $43(47,8 \%)$ responden tidak memiliki televisi yang diletakkan di dalam kamar. Hasil uji analisis bivariat, ditemukan adanya hubungan yang bermakna (nilai $\mathrm{p}<0,005)$ antara durasi paparan media elektronik 
Maudina Hati Fatimah Diantoro dkk: Hubungan durasi paparan media elektronik terhadap pola tidur anak usia 10-13 tahun

Tabel 1. Karakteristik subjek penelitian

\begin{tabular}{lc}
\hline Karakteristik & $\mathrm{n}(\%)$ \\
\hline Jenis kelamin & \\
$\quad$ Laki-laki & $30(33,3)$ \\
Perempuan & $60(66,7)$ \\
Kelompok usia (tahun) & \\
10 & $46(51,1)$ \\
11 & $25(27,8)$ \\
12 & $3(3,3)$ \\
13 & $16(17,8)$ \\
Durasi paparan media elektronik & \\
$\quad$ Kurang dari 2 jam perhari & $14(15,6)$ \\
$\quad$ Lebih dari 2 jam perhari & $76(84,4)$ \\
Gangguan tidur & \\
$\quad$ Ya & $65(72,2)$ \\
$\quad$ Tidak & $25(27,8)$ \\
Pencahayaan saat tidur & \\
$\quad$ Ya (Terang) & $50(55,6)$ \\
Tidak (Gelap) & $40(44,4)$ \\
Suara bising yang mengganggu saat tidur & \\
$\quad$ Ya & $31(34,4)$ \\
Tidak & $59(65,6)$ \\
Penempatan televisi di kamar yang dinyalakan saat tidur & \\
$\quad$ Ya & $47(52,2)$ \\
Tidak & $43(47,8)$ \\
\hline
\end{tabular}

Tabel 2. Hubungan durasi paparan media elektronik, jenis kelamin, pencahayaan, suara bising dan televisi di kamar dengan gangguan tidur diuji dengan metode chi-square

\begin{tabular}{|c|c|c|c|c|c|}
\hline & & \multicolumn{2}{|c|}{ Gangguan tidur } & \multirow{2}{*}{ Total } & \multirow{2}{*}{$\mathrm{P}$} \\
\hline & & Ada $(\%)$ & Tidak (\%) & & \\
\hline \multirow{2}{*}{ Durasi paparan media elektronik } & 2 jam perhari & $58(76,3)$ & $18(23,7)$ & 76 & \multirow{2}{*}{0,043} \\
\hline & 2 jam perhari & $7(50)$ & $7(50)$ & 14 & \\
\hline \multirow{2}{*}{ Jenis kelamin } & Laki-laki & $21(70)$ & $9(30)$ & 30 & \multirow{2}{*}{0,739} \\
\hline & Perempuan & $44(73,3)$ & $16(26,7)$ & 60 & \\
\hline \multirow{2}{*}{ Pencahayaan saat tidur } & Terang & $36(72)$ & $14(28)$ & 50 & \multirow{2}{*}{0,958} \\
\hline & Gelap & $29(72,5)$ & $11(27,5)$ & 40 & \\
\hline \multirow{2}{*}{ Suara bising saat tidur } & Ada & $25(80,6)$ & $6(19,4)$ & 31 & \multirow{2}{*}{0,196} \\
\hline & Tidak & $40(67,8)$ & $19(32,2)$ & 59 & \\
\hline \multirow{2}{*}{ Penempatan televisi di kamar } & Ada & $34(72,3)$ & $13(27,7)$ & 47 & \multirow{2}{*}{0,979} \\
\hline & Tidak & $31(72,1)$ & $12(27,9)$ & 43 & \\
\hline
\end{tabular}

dengan munculnya gangguan tidur pada anak usia 1013 tahun, tetapi tidak ditemukan adanya hubungan yang bermakna antara jenis kelamin, pencahayaan saat tidur, suara bising saat tidur, dan penempatan televisi yang menyala si kamar terhadap munculnya gangguan tidur pada anak usia 10-13 tahun.

\section{Pembahasan}

Berdasarkan hasil penelitian, terdapat 76 (84\%) subjek menggunakan media elektronik dengan durasi lebih dari dua jam perhari sedangkan subjek penelitian yang menggunakan media elektronik kurang dari 2 jam perhari hanya $14(16 \%)$ subjek. Secara statistik 
didapatkan hasil yang bermakna antara durasi paparan media elektronik lebih dari 2 jam terhadap pola tidur anak usia 10-13 tahun. Hal ini sesuai dengan penelitian yang dilakukan oleh Parent $\mathrm{dkk}^{7}$ yang melaporkan bahwa gangguan tidur yang muncul pada anak prasekolah setelah 6 jam paparan media elektronik perharinya. Sementara pada anak usia sekolah dan remaja, gangguan tidur akan meningkat pada paparan media elektronik secara lama 9 sampai dengan 10 jam atau lebih perhari. ${ }^{7}$

Subjek penelitian yang mengalami gangguan tidur $65(72,2 \%)$ anak. Hasil ini jauh lebih besar dibandingkan hasil yang dilaporkan studi lain dengan menggunakan metode SDSC di Indonesia, Natalita $\mathrm{dkk}^{3}$ melaporkan 62,5\% dan Haryono $\mathrm{dkk}^{2}$ melaporkan $62,9 \%$. Perbedaan ini dapat disebabkan oleh perbedaan karakteristik subjek penelitian yang meliputi usia serta populasi yang digunakan. Penelitian yang dilakukan oleh Natalita dkk dan penelitian Haryono dkk melibatkan subjek penelitian berusia 12-15 tahun, sedangkan kami melibatkan subjek penelitian berusia 10-13 tahun. Hal tersebut didukung dengan laporan penelitian di tahun 2012 yang melibatkan 5 negara, termasuk Indonesia, bahwa lebih dari $80 \%$ anak usia 10 13 tahun telah memiliki akses telepon selular pribadi ${ }^{5}$ sehingga berpotensi menimbulkan gangguan tidur yang lebih besar.

Mayoritas media elektronik sekarang secara umum menggunakan LED (Light-emitting diodes) sebagai sumber pencahayaan yang berasal dari cahaya biru (blue light). Cahaya biru yang dilepaskan oleh layar elektronik dianggap menyerupai cahaya matahari sehingga fotoreseptor melanopsin bereaksi seakanakan saat menggunakan layar elektronik sebagai waktu siang. Akibatnya kelenjar pineal yang berada di otak berhenti untuk melepaskan hormon melatonin yang berfungsi sebagai pemicu kantuk dan berakibat pada pergeseran ritme sirkardian sehingga berujung pada munculnya gangguan tidur. ${ }^{8}$ Penelitian yang membandingkan antara paparan cahaya (blue light dan white light) pada kelompok usia muda (rerata usia 25 tahun) dan kelompok usia tua (rerata usia 64 tahun) didapatkan bahwa terdapat penurunan pelepasan hormon melatonin di malam hari hanya pada kelompok usia muda akibat paparan blue light dan white light.' Paparan cahaya tersebut walaupun hanya dalam durasi pendek, dapat menyupresi hormon melatonin pada anak sebesar 1,9-2,7 kali lipat dibandingkan dewasa. ${ }^{10}$ Anak dengan pre-mid pubertas menunjukkan supresi hormon melatonin yang lebih tinggi dibandingkan pada anak dengan late-post pubertas. ${ }^{11}$

Pada penelitian ini didapatkan bahwa jenis kelamin tidak memiliki hubungan dengan gangguan tidur pada anak. Akan tetapi, terlihat kecenderungan bahwa perempuan memiliki prevalensi gangguan tidur yang lebih besar dibandingkan laki-laki. Penelitian yang dilakukan pada populasi umum dengan membandingkan prevalensi kejadian gangguan tidur pada pria dan wanita didapatkan hasil bahwa wanita mengalami tingkat gangguan tidur lebih tinggi dibandingkan pria dalam semua golongan usia. ${ }^{12}$ Penelitian yang menggunakan sampel penelitian berusia 10-35 tahun didapatkan hasil bahwa perempuan mengalami gangguan tidur yang lebih besar dibandingkan pria. Namun, penelitian lebih lanjut diperlukan untuk menentukan alasan yang mendasari dalam perbedaan jenis kelamin ini. ${ }^{13}$

Suara bising, pencahayaan saat tidur, dan televisi di dalam kamar merupakan kondisi lingkungan yang ditanyakan pada subjek. Subjek yang mengalami paparan suara bising sebanyak $31(34,4 \%)$ anak. Suara bising dapat berasal dari lingkungan sekitar yang tidak dapat diintervensi untuk berhenti seperti suara kendaraan di jalan raya atau suara lintasan kereta api. Kami tidak menemukan hubungan yang bermakna antara suara bising dengan munculnya gangguan tidur. Penelitian terdahulu melaporkan bahwa gangguan tidur baru muncul dengan paparan suara bising sebesar 65 dB. ${ }^{14}$ Penelitian lain melaporkan bahwa gangguan kesehatan muncul pada paparan sebesar $55 \mathrm{~dB}$ secara terus menerus dengan penyebab utama adalah suara bising kendaraan di jalan raya yang diikuti dengan suara bising dari rel kereta api. ${ }^{15}$

Penelitian yang menghubungkan antara suara bising saat malam dengan gangguan tidur menyebutkan bahwa intensitas suara melebihi $55 \mathrm{~dB}$ tergolong berbahaya dengan tingkat kejadian gangguan kesehatan semakin besar mulai dari gangguan tidur hingga risiko penyakit kardiovaskular. ${ }^{17}$ Waktu dari paparan suara bising juga dianggap relevan terhadap munculnya gangguan pada tidur. Studi eksperimental menunjukkan bahwa paparan suara bising pada awal waktu tidur dapat dikompensasi selama sisa malam. ${ }^{18}$

Subjek lebih banyak menggunakan pencahayaan atau tidak mematikan lampu ketika tidur terdapat 50 $(55,6 \%)$ anak. Penelitian sebelumnya melaporkan bahwa tidur menggunakan cahaya redup atau mematikan lampu saat tidur bermakna meningkatkan hormon 
melatonin. Hal tersebut berpengaruh terhadap peningkatan kualitas tidur yang lebih baik. ${ }^{19}$ Namun, kami tidak mendapatkan hubungan yang bermakna antara pencahayaan yang digunakan saat tidur dengan munculnya gangguan tidur pada anak.

Terdapat $47(52,2 \%)$ anak yang menggunakan televisi untuk menonton dalam kamar tidur, tetapi tidak terdapat hubungan yang bermakna terhadap munculnya gangguan tidur. Penelitian oleh Chaput $\mathrm{dkk}^{20}$ melaporkan hasil bahwa anak yang memiliki 2-3 media elektronik di dalam kamar memiliki durasi screentime yang lebih besar dibandingkan dengan anak tanpa media elektronik di kamar. Durasi tidur tidak terpengaruh dari banyaknya media elektronik di dalam kamar. Namun, penurunan kualitas tidur terjadi dengan penempatan minimal 2 media elektronik di kamar. Kualitas tidur yang baik akan terganggu dengan penggunaan media komunikasi satu jam sebelum waktu tidur. ${ }^{21}$

Peneliti tidak mengontrol faktor lain, seperti pengukuran intensitas suara bising saat tidur, pengambilan data melalui anamnesis yang bersifat subjektif karena bergantung pada interpretasi anak serta instrumen penelitian yang masih menggunakan kuesioner yang memungkinkan terjadinya bias.

\section{Kesimpulan}

Terdapat 76 anak dari 90 anak berusia 10-13 tahun di Tembalang, Semarang dengan paparan media elektonik melebihi dari yang disarankan oleh American Academy of Pediatrics (AAP). Terdapat hubungan yang bermakna antara durasi paparan media elektronik lebih dari dua jam dengan gangguan tidur anak usia 10-13 tahun.

\section{Daftar pustaka}

1. Dewald JF, Meijer AM, Oort FJ, Kerkhof GeA, Bogels SM. The Influence of Sleep Quality, Sleep Duration and Sleepiness on School Performance in Children and Adolescents: A metaAnalytic Review. Sleep Med Rev 2010;14:179-89.

2. Haryono A, Rindiarti A, Arianti A, dkk. Prevalensi gangguan tidur pada remaja usia 12-15 tahun di sekolah lanjutan tingkat pertama. Sari Pediatri 2017;11:149.

3. Natalita C, Sekartini R, Poesponegoro H. Skala gangguan tidur untuk anak (SDSC) sebagai instrumen skrining gangguan tidur pada anak sekolah lanjutan tingkat pertama. Sari Pediatri 2017;12:365.

4. Gayatri G, Rusadi U, Meiningsih S, Mahmudah D, Sari
D, Nugroho AC. Perlindungan Pengguna Media Digital Di Kalangan Anak Dan Remaja Di Indonesia. J Penelit dan Pengemb Komun dan Inform 2015;6:1-18.

5. GSMA NTT DOCOMO. Children's Use of Mobile Phone An International Comparison(serial online). 2012. Diakses pada 20 Maret 2019. Didapat dari : https://www.gsma.com/latinamericalwp-

6. Swartz MK. Taking Another Look at Screen Time for Young Children. J Pediatr Heal Care 2017;31:141.

7. Parent J, Sanders W, Forehand R. Youth screen time and behavioral health problems: The role of sleep duration and disturbances. J Dev Behav Pediatr 2016;37:277-84.

8. Tosini G, Ferguson I, Tsubota K. Effects of Blue Light on the Circadian System and Eye Physiology. Mol Vis 2016;1:61-72.

9. Gabel V, Reichert CF, Maire M, dkk. Differential impact in young and older individuals of blue-enriched white light on circadian physiology and alertness during sustained wakefulness. Sci Rep 2017;7:1-13.

10. Lee S, Matsumori K, Nishimura K, Nishimura Y, Ikeda Y, Eto T. Melatonin suppression and sleepiness in children exposed to blue-enriched white LED lighting at night. Physiol Rep 2018;6:1-9.

11. Crowley SJ, Cain SW, Burns AC, Acebo C. Increased Sensitivity of the Circadian System to Light in Early/midpuberty. J Clin Endocrinol Metab 2015;100:1-7.

12. Grandner MA. Sleep, Health, and Society. Sleep Med Clin 2018;12:1-22.

13. Oyegbile TO, Delasobera BE, Zecavati N. Gender differences in sleep symptoms after repeat concussions. Sleep Med 2017;40:110-5.

14. Tobollik M, Hintzsche M, Wothge J, Myck T, Plass D. Burden of Disease Due to Traffic Noise in Germany. Int J Environ Res Pub Health 2019;16:6-12.

15. Jronsinska D, Heroux M, Wilkhu P, dkk. Development of the WHO environmental noise guidelines for the European Region : an introduction. Int J Environ Res Pub Health 2018;15:1-7.

16. Guski R, Schreckenberg D, Schuemer R. WHO Environmental Noise Guidelines for the European Region: A Systematic Review on Environmental Noise and Annoyance. Int J Environ Res Public Health 2017;14:1-39.

17. Hume KI, Brink M, Basner M. Effects of environmental noise on sleep. Noice and Helath 2012;14:297.

18. Röösli M, Brink M, Rudzik F, dkk. Associations of Various Nighttime Noise Exposure Indicators with Objective Sleep Efficiency and Self-Reported Sleep Quality : A Field Study. Int J Environ Res Pub Health 2019;1-13.

19. Rahman SA, Lockley SW, Disorders C. The effects of spectral tuning of evening ambient light on melatonin suppression, alertness and sleep. Physiol Behav 2018;177:221-9.

20. Chaput J, Leduc G, Boyer C, dkk. Electronic screens in children's bedrooms and adiposity, physical activity and sleep: Do the number and type of electronic devices matter? Can J Publik Health 2014;105:273-9.

21. Dube N, Khan K, Loehr S, Chu Y, Veugelers P. The use of entertainment and communication technologies before sleep could affect sleep and weight status : a population-based study among children. Int J Behav Nutr Phys Act 2017;14:1-15. 